\title{
NEWS
}

\section{Studying at UCL Institute of Archaeology: Past and Present}

\author{
Charlotte Frearson and Jennifer C. French
}

Ranked in the top five in the UK for archaeology, for the $12^{\text {th }}$ year in a row, in The Guardian University Guide League Tables.

Ranked in the top five for student satisfaction in The Complete University Guide 2019 League Table of UK archaeology departments (published in May 2018).

Twitter: @UCLarchaeology

Facebook: https://www.facebook.com/UCLArchaeology_

Instagram: ucl_archaeology

\section{Research-led Teaching}

Studying at UCL Institute of Archaeology (IoA) is an experience like no other. Consistently rated one of the best archaeology departments in the UK, the IoA offers a unique experience to each of its students, at both the undergraduate and graduate levels. Students at all stages of their academic careers are encouraged to engage with current archaeological research-guided by a 70-strong academic staff who are amongst the leaders in their fields. To all those considering embarking on the adventure of a lifetime, here's how students at the Institute connect and engage with the very best archaeological research the UK has to offer!

With seven undergraduate degree programmes and twenty masters' degrees, the IoA provides a huge variety of options

UCL Institute of Archaeology, London WC1H OPY, UK

Corresponding author: Jennifer C. French (jennifer.french@ucl.ac.uk) for its students, covering a vast range of archaeological topics in both theoretical and practical terms. A degree at the Institute aims to challenge student expectations and develop a wide range of transferable skills, so demands time and commitment. Each degree has a distinct character, and is structured around specified core courses and a dissertation (Figure 1).

Information on both undergraduate and masters' degree courses can be found at: http:// www.ucl.ac.uk/archaeology/studying.

Fieldwork also plays a vital role in the student experience, with undergraduates undertaking a minimum of 70 days throughout their three years (funding towards the 70 days of fieldwork is available for all undergraduates). We currently have students on excavation in North, South and Central America, Europe, Africa and Asia. Working in the field helps students to gain a better understanding of the quality and range of data that can be collected from excavation and survey, or offers them the experience of working 


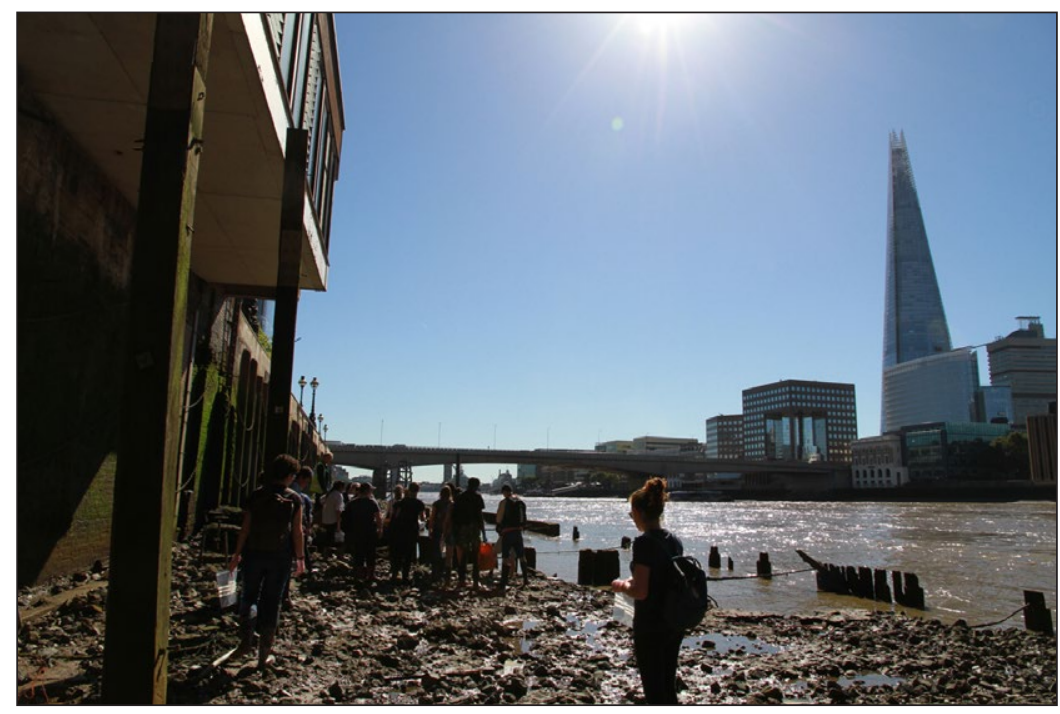

Figure 1: Fieldwork on the Thames with staff and students from the Institute of Archaeology (Photo Charlotte Frearson).

at heritage sites or in museums, and the chance to travel to parts of the world that they have been learning about in their coursework.

The Institute also has the largest and most diverse community of archaeology research students of any university in the world. Our academic staff offer PhD supervision across a wide topical, geographical and chronological range, and with the support of a personal supervisor students research an individual topic over three years. Information on $\mathrm{PhD}$ and staff research interests can be found at: http:// www.ucl.ac.uk/archaeology/people.

\section{Life at the Institute}

Located in the heart of Central London, UCL's campus puts students within easy walking distance of museums, theatres, cultural life and even on-going archaeological excavations. The Institute itself sits on the northern side of Gordon Square, and is home to all our staff, undergraduates, masters' and PhD students. Amongst its many charms, the Institute houses: an exceptional archaeological library, world-renowned collections, laboratories, computing and photographic facilities, and much, much more. All of our students are encouraged to participate in Institute life, with the Society of Archaeology Students (SAS) and the Society of Archaeology Masters Students (SAMS) running a wide range of social and academic events throughout the year.

Details of open days can be found at: http://www.ucl.ac.uk/archaeology/ studying/undergraduate.

http://www.ucl.ac.uk/archaeology/ studying/masters/degrees.

\section{The Student Perspective}

Want to know what it is really like to study at the IoA? Here are a few stories from our current students to give you a little peek into the student experience.

Tarsha Coleman ( $1^{\text {st }}$ year undergraduate, BA Archaeology and Anthropology)

UCL's Institute of Archaeology was my first choice originally because of its incredible reputation and expert lecturing staff. The breadth and depth of courses on offer allowed me to study briefly the whole world through time or explore one period in extreme detail with leading lecturers in the field guiding the way. Another reason I was drawn to the course is the 70 days of funded fieldwork allowing everyone an equal opportunity to experience digs. 
I've just finished my first year of the BA Archaeology and Anthropology course but already feel like I've covered an amazing collection of topics. Within archaeology we've looked at the first humans, social complexity, the rise and fall of empires and the theoretical history of the subject itself. Within anthropology we've studied past anthropologists and their endeavors, nature and culture divides, gender, and globalization.

The variety of teaching methods within the IoA really helped me to learn, and includes lectures, tutorials, museum visits, practical object handling and a huge online collection of texts. The IoA's library has become my favourite place to study with plant life surrounding the desks.

While the IoA's reputation drew me to $\mathrm{UCL}$, its sense of community makes it hard for me to imagine life anywhere else. The people I have met have made my first year truly unforgettable, I have yet been unable to find another subject where the students feel as much like a group as we all do. The most significant part in the making of this community is the PrimTech course at the start of year 1. In fresher's week everyone goes to
Chichester to take part in an experimental archaeology course for a few days. Camping sometimes in questionable weather, spending days doing amazing activities (flint knapping, cheese making, metallurgy and more) and spending the evenings round the fire creates friendships that last.

This community is strengthened by the fieldwork we all go on together. When finishing first year I attended the Downley 2018 excavation. In addition to Downley, I have also done practical work with the Thames Discovery Programme where we worked on the Thames Foreshore. I still have many days of my fieldwork requirement to go and look forward to all the opportunities this will give me to research, travel and learn (Figure 2).

Anyone with a passion for the past will thrive at the IoA, I would recommend my course highly due to its variety of subjects, available fieldwork opportunities, and especially the incredible support staff who make the IoA a home to so many students.

Rosalyn Christian ( $3^{\text {rd }}$ Year Undergraduate, BSc Archaeology, Leaver 2018)

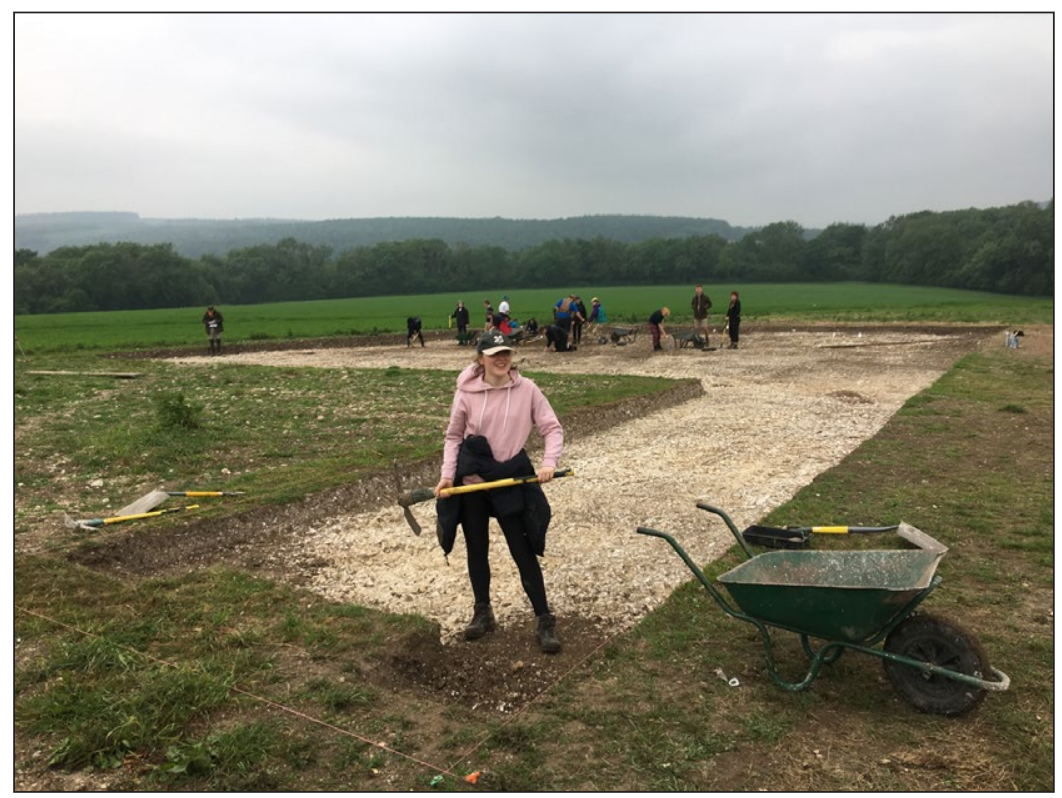

Figure 2: Current IoA Archaeology and Anthropology student Tarsha Coleman on excavation (Photo Tarsha Coleman). 
I started studying at the IoA in 2015, on the Classical Archaeology and Classical Civilisations degree programme (Figure 3). I'm the first generation of my family to attend university so I didn't have any reference for what it would be like: How would I get to know the people on my degree? Would I be able to juggle part time work, studying, and volunteering? How do I seek out unique opportunities to improve my CV? What if I'm just no good at digging?

Within the first few weeks at the IoA all of my questions were answered. I've often found it a challenge to settle in to new schools and new workplaces so I was beyond relieved when the IoA began to feel like a home away from home. The supportive environment which focussed not only on our success and progress, but emotional wellbeing, was in large part due to the SAS's efforts in representing our voices to the staff and ensuring we were included. PrimTech was an

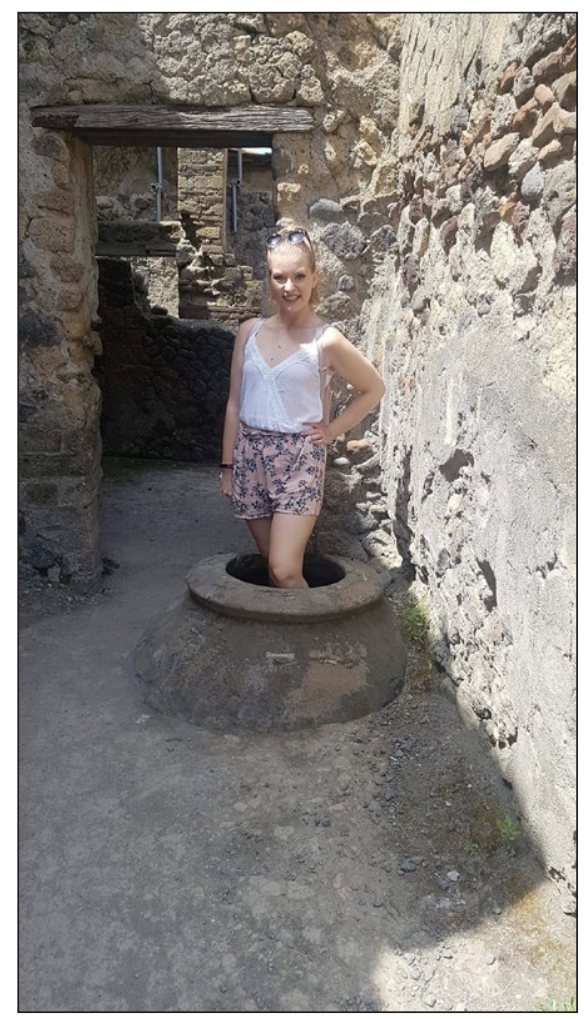

Figure 3: Recently graduated IoA student Rosalyn Christian exploring Herculaneum (Photo Rosalyn Christian). exciting introduction to the students and lecturers, everyone was very welcoming and we were on an equal playing field with muddy clothes and tent hair. I couldn't have asked for a better start to my university education. Academically I was both challenged and supported by personal tutors and degree tutors and we had excellent sessions in the British Museum discussing artefacts and public archaeology. The lecturers were willing to put in just as much work and care into my education as I was, and I have won the Sessional Prize for my academic achievements.

The range of courses offered by the Institute enabled me to explore Roman Archaeology from different angles, and the scientific modules (human remains, zooarchaeology, archaeological science, plants in archaeology) captured my interest most. I chose a lab based dissertation analysing Romano-British zooarchaeological remains in my second year, and at the beginning of my third year I changed my degree title to Archaeology BSc to reflect my skill set. The freedom of module choice at the IoA has given me the opportunity to specialise in the Roman Archaeology of Britain using scientific techniques. My dissertation was one of the toughest challenges I have faced but I am very proud of the work I have put in. I didn't know if my work at undergraduate level would ever be significant enough to contribute to the wider study of archaeology, but my dissertation gave me the platform to begin to answer some long-standing questions surrounding the rural archaeology of Roman Hertfordshire. I'm delighted to have made an impact.

The presentation skills and strength for pastoral care I developed from my role as SAS president encouraged me to apply for tutoring positions. For 18 months I have been lecturing in Latin, Roman art history and general archaeology at extra-curricular schools and camps for gifted children who have no other access to the study of the Classical World. This summer I will be site supervisor for the first time at an excavation in one of these summer schools. The transferable skills from my archaeology degree have also proved well sought after in an office environment too. Since summer 2016 I have 
worked as a project co-ordinator for London Vision, a sight loss charity in London. Now I'm graduating, I will be taking on a full-time role. My roles include building networks for blind students in London and planning events for the other networking groups organised by the charity. I have presented at a National Conference for University Disability Departments, and contributed to the organisation and successful operation of a forum at the Houses of Parliament. None of these achievements would have been possible without the experiences of my degree. I'm sad to leave behind what feels like a family at the Institute, but I am so very grateful for the person who I have become.

Hannah Page (current PhD student, BA Egyptian Archaeology, 2008-2011, MA Artefact Studies, 2011-12)

I started my archaeological and academic journey at the UCL Institute of Archaeology nearly 10 years ago in 2008. It guided me through my BA and MA to now, when I am nearing the end of my PhD. Nothing speaks louder of my praise for the Institute than my confidence in it seeing me through these stages, academically, professionally and personally (Figure 4).

The range of courses, breadth of knowledge and encouragement of the teaching staff have enabled me to explore and pursue my interests, and given me the opportunities to work and become a specialist in my field. Furthermore, the teaching and support staff have provided immeasurable help and advice during difficult times. The range of training and my practical experiences have provided me with the confidence and ability to embark on exciting work and personal journeys, including: employment as a finds liaison assistant with the Portable Antiquities Scheme; co-ordinating and teaching an archaeological field school in Sudan; conducting fieldwork and research in Uganda, South Africa and Botswana; teaching archaeology at junior school, secondary school, BA and MA level; presenting my research at international archaeology conferences.

Therefore, I could not recommend the IoA highly enough to anyone interested in studying archaeology, whether you wish to become an academic archaeologist or not. The experiences, contacts and friends you make here will most certainly stay with you.

\section{Careers: A future in Archaeology and other sectors}

A degree in archaeology prepares you for work in any sector after graduation, with the most transferable skills of any degree. At the IoA, we have two internal careers advisors, one

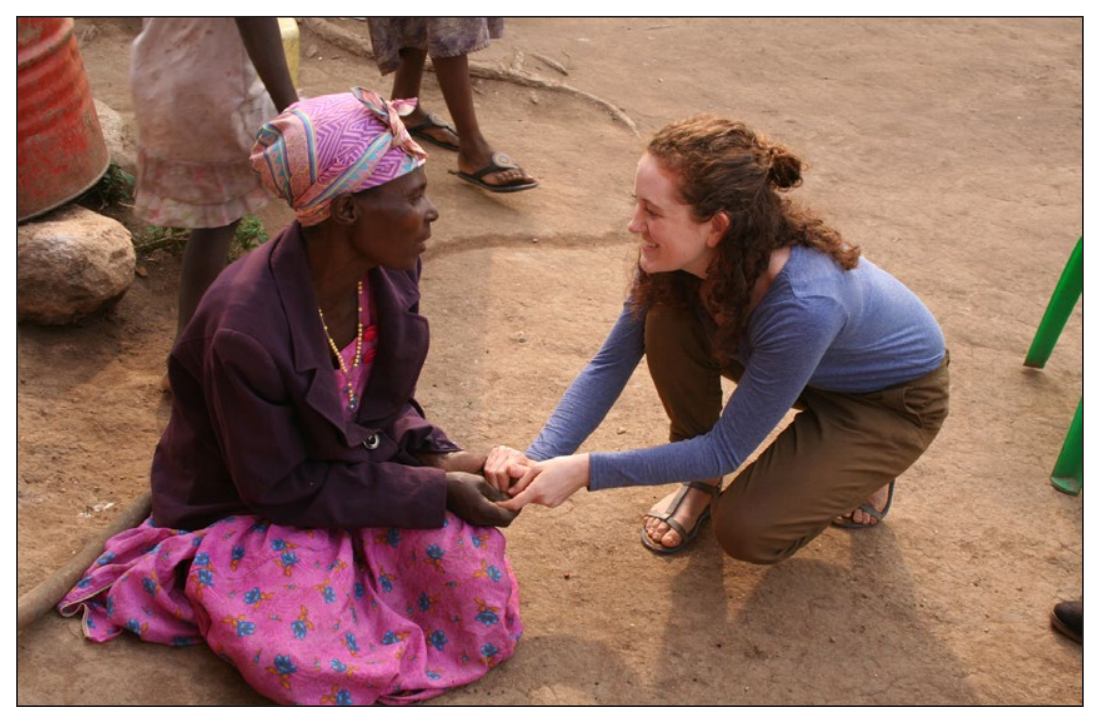

Figure 4: IoA PhD student Hannah Page conducting ethnoarchaeological research with a local potter in Uganda in 2017 (Photo Hannah Page). 
academic and one professional, to help you throughout your studies. We work closely with the UCL Careers office offering students support, guidance and opportunities regarding careers in archaeology, heritage, and related fields and across all job sectors. We run annual careers days (open to both undergraduate and postgraduate students) and maintain strong links with London Museums, heritage bodies and our alumni to aid students in securing volunteer positions in their spare time.

\section{Alumni Reflections}

Graduates from the IoA go on to do amazing things with their degrees, from the traditional academic route to being policy makers in government and even becoming well-known TV personalities. Here are a few of their stories.

\section{Hélène Rey (BSc Archaeology 2014)}

I still remember the first time I stepped foot inside the IoA, at the end of a long week of university interviews. I must say that UCL was not my top choice - in the small Alpine village I come from, no one has ever heard of UCL. But I fell in love at first sight. And I never regretted it: not only was my time at the IoA among my most stimulating experiences, intellectually and practically, it also brought me precious skills that I have been using ever since.

After completing my BSc in Archaeology, I moved to the United States for a MA in (modern) Middle Eastern Studies, with a focus in sociology, at the University of Chicago. If many saw this as a change of direction, for me it was very much a continuation of my undergraduate education. The rigorous and interdisciplinary training I had received at the IoA proved to be invaluable for my postgraduate studies, from applied statistics courses where I could rely on what I had learnt through archaeological surveys and methods classes, to history modules, where my ability to think beyond the text always brought me fresh perspectives. Even in theory classes, I discovered how well-prepared I was thanks to readings done in various courses around the IoA. And being trained to understand the development of various types of societies was very useful, from political sciences courses to anthropology, not to mention sociology.

Currently I work for a human rights/humanitarian organisation in Switzerland, with a special responsibility for projects in the Middle East, where I travel regularly (Figure 5). This means that-alas!-I do not get to do any artefact or bone analysis nor any excavations. But that does not mean that my archaeological skills are not often put to use. The first time I realised this was in a small town in northern Iraq, just after the withdrawal of the Islamic State from the area. I was walking in a town in ruins, but I could see beyond that to the town that once was. Fragments of objects on the ground, destroyed buildings, everything meant more to me than it did to my colleagues. They were not mere signs of atrocities: they were also living memories of a culture on the brink of extinction. Having developed good geospatial awareness during my years at the IoA proved extremely helpful in understanding how things fit together and also in avoiding potential danger. And nothing prepares someone better for the sight of bodies forgotten under the rubble of western Mosul than having worked on burial sites. This past I am confronted with might be extremely recent, but my time at UCL allows me to look at it with helpful analytical distance.

Archaeology is also such a powerful way to connect to people. In Iraq, especially after the destruction of many archaeological sites, the people I encounter are always keen on talking about the past and their connection to it. After all, many of them still call themselves "Assyrians." I will also always remember a summer evening in Sebastia, a village in Palestine, when the face of my host suddenly lit up at the mention of the IoA: one of his personal heroes is the IoA's Kathleen Kenyon, who had worked in the area.

I haven't been able to go back to London since graduation, but one thing is certain: once I do, my first stop will be my home, the IoA.

\section{Lisa Grimm (MA Archaeology 1997)}

I fell into the tech industry entirely by accident during my MA in Archaeology at the IoA in the 


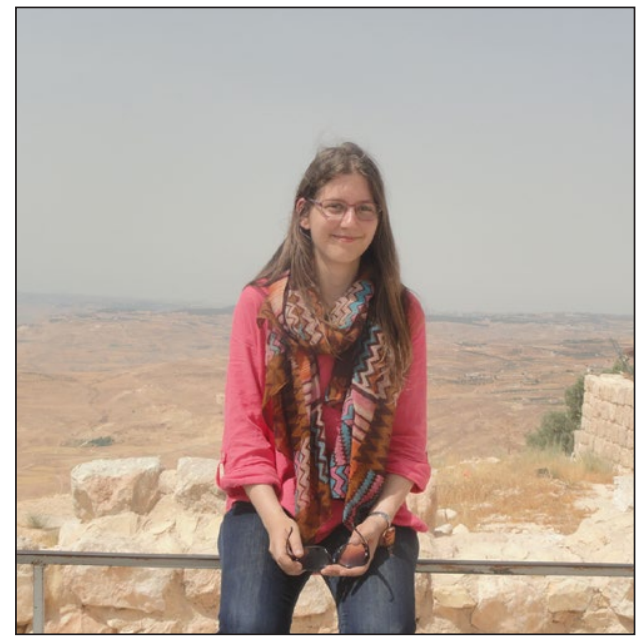

Figure 5: Former IoA student Hélène Rey on Mount Nebo, Jordan (Photo Hélène Rey).

late 1990s; I designed and built my first website for fun on UCL's servers as a way to keep track of the (then relatively few) interesting places on the internet to geek out over later European prehistory, which was my focus during my degree (I can still tell you an awful lot about the trade of amber during the Bronze Age). Using those self-taught coding skills, I landed a part-time job as a web developer at Time Out, and my career snowballed from there. Since then, I've worked for large tech companies like Hewlett-Packard and Juniper Networks in Silicon Valley, as well as in hybrid nerdy roles in museums, libraries, publishing and academia across the US. I now lead the Worldwide Media Taxonomy team at Amazon.com, from their Seattle headquarters, where my amazing staff ensure you can find all your Prime Video, Alexa Skills, Music and many more must-haves, wherever you are in the world (Figure 6). While it may not sound like it from that description, I actually use the things I learned as a UCL postgrad on a daily basis as an Amazonian, and I have throughout my career.

Research, writing, coding and classification are all key parts of my role; using data to identify patterns in human behaviour is something that's just as applicable to the living as to the long-dead, and being able to tease out what's happening from a few isolated-but-potentiallyconnected data points powers decision-making in this industry. Having an understanding of how culture changes and spreads gives me a major advantage in my career, especially when it comes to driving always-dreaded 'change management' initiatives, and living and working in such a diverse, globally-connected city like London set me up for success from the start. My archaeology background has also been a useful calling card for some of my side projects: I had a beer history column at Serious Eats largely because I had a 'recognized qualification' to write about that aspect of beer (I'm also a BJCPcertified beer judge) - and that was before factoring in the reputation archaeologists have for liking a drink. I've been fortunate to work on some exciting projects in the digital humanities and digital libraries spaces because of what I learned at the IoA; it's given me an enviable number of so-called 'transferable skills.'

I remain a passionate advocate for archaeology, preservation and cultural heritage, as well as diversity and inclusion in the tech industry. I've brought these interests together as a writer, conference speaker and mentor to those looking to make a career change into tech, and I encourage anyone with a multidisciplinary background like archaeology to explore the other opportunities their deep and varied expertise allows; it's truly an education that let me choose my own continuing adventure.

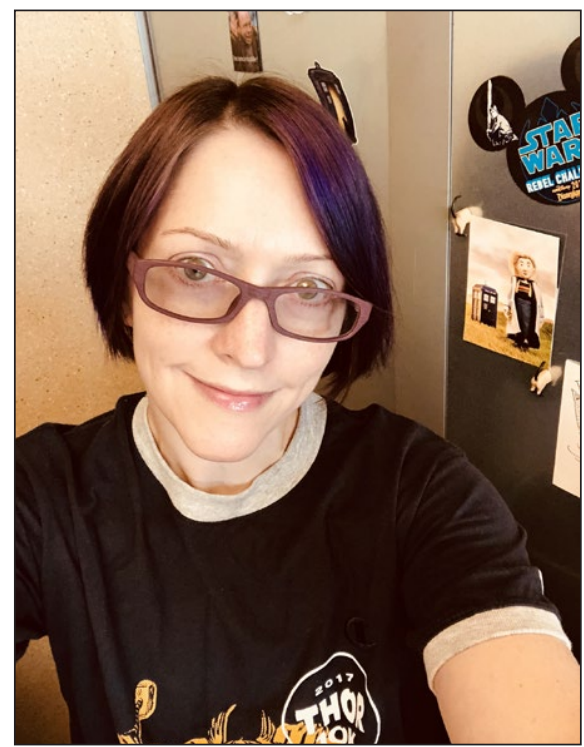

Figure 6: Former IoAstudent Lisa Grimm who now works in the tech industry (Photo Lisa Grimm). 